\title{
Sweetness analysis of Lower Goru sandstone intervals of the Cretaceous age, Sawan gas field, Pakistan
}

\author{
${ }^{1}$ Department of Earth Sciences, Quaid-i-Azam University, Islamabad 45320, Pakistan; *Corresponding author, E-mail: tahir2rd@yahoo.com; \\ tazeem@qau.edu.pk \\ ${ }^{2}$ School of Geophysics and Information Technology, China University of Geosciences, Beijing 100083, China \\ ${ }^{3}$ Institute of Geology, University of the Punjab, Lahore 54590, Pakistan
}

(Received: March 30, 2018; Revised accepted: November 28, 2018)

https://doi.org/10.18814/epiiugs/2018/018019

$B$ and $C$ sands of the Lower Goru Formation of Cretaceous are proven reservoirs in different parts of the Middle and Lower Indus Basin, Pakistan. Most of the discoveries in this basin have been made in structural traps. However, in Sawan gas field; structural inversion, deep burial depth and heterogeneity of reservoir intervals make it difficult to demarcate the sweetness zones through conventional seismic analysis. In this work, different data sets have been integrated through constrained sparse spike inversion to mark sweetness zones in B and $C$ sands of this formation. $C$ sand contains four sweetness zones; the main sweetness zone is located towards the east while three subtle sweetness zones were identified towards the west of Sawan fault. The location of producing and nonproducing wells within the sweetness and outside of sweetness zones confirms the credibility of this work. $B$ sand includes three sweetness zones located towards the west of Sawan fault. Moreover, inverted porosity results not only show good agreement with the porosity log of blind well (Sawan-02) but also show good matching with the core porosities. Hence integration of different data sets leads to demarcate the accurate location, size and extent of the sweetness zones.

\section{Introduction}

Conventional seismic data interpretation techniques are commonly used to analyze the large scale structural and stratigraphic traps (Varela et al., 2006). The reliability of the results obtain is purely based on the identification of different kinds of sedimentary geometries and structural style and then to relate them with the geologic features of interest (Balch, 1971; Possato et al., 1983). However, when the objective is to find the accurate location, size, vertical and horizontal extent of the sweet zones then quantitative interpretative methods need to be applied (Huang et al., 2009; Wagner et al., 2012). Different types of quantita- tive methods and techniques such as seismic attributes, amplitude versus offset (AVO) analysis, neural network and rock physics models are used to analyze the seismic amplitudes anomalies (Avseth et al., 2005; Chi and Han, 2009; He et al., 2011; Khalid et al., 2014; Azeem et al., 2015, 2017). Mostly these techniques provide very accurate results on the basis of 3D seismic data analysis. However, in geological complex reservoir zones, quantitative analysis based on single 2D seismic data set does not provide reliable results. These complex features can be accurately interpreted by integrating different types of data sets (Mukerji et al., 2001).

Integration of different kinds of data sets minimizes the uncertainty in prediction of rock properties, subtle stratigraphic traps and sweet zones in the target zone (Grijalba-Cuenca et al., 2000; Azeem et al., 2017; Ali et al., 2018). However, the integration of 2D seismic data and well $\log$ data sets requires more care when used for seismic reservoir characterization, as they are most likely subjected to errors (Jarvis, 2006). To overcome this problem, seismic inversion is the key, which can tightly combine the fine scale vertical details of well logs with laterally dense measurements of seismic data (Sams et al., 1999; Gunning and Glinksy, 2004). The tighter integration of these data sets through seismic inversion not only helpful to demarcate the geometry of the subsurface structures accurately but also minimize the risk of uncertainty.

In seismic inversion process, wavelet is removed from seismic data which makes it possible to correlate the subsurface lithologies with seismic signatures (elastic properties) in better way. These derived elastic properties are associated with specific depth or time; therefore, elastic to reservoir properties can be transformed point by point. So, seismic inversion provides the information about the actual rock properties and creates a bridge between the subsurface geology and its digital representation in the form of seismic amplitude (Latimer et al., 2000).

At present different type of algorithm are used to perform the seismic inversion. Choice of these techniques depends upon the availability of data sets, geological conditions and existing problems to be solved (Filippova et al., 2011). Constrained sparse spike inversion (CSSI) is based on sparse inverse deconvolution (Oldenburg et al., 1983). CSSI 
uses data constrains to reduce the non-uniqueness and produces a reliable and simplified version of the subsurface in the form of acoustic impedance (Simm et al., 2014). However, the inverted impedance model lacks of low frequency information as it is based on band limited seismic data.

Low frequency information can be obtained from well logs and need to be merged with the band limited inverted model in order to get the accurate and precise information about the subsurface rocks in the form of acoustic impedance (Latimer et al., 2000; Barclay et al., 2008). Acoustic impedance is a rock property so; reservoirs properties can be obtained from inverted acoustic impedance by implementing obtained linear or non-linear relationships (Hampson et al., 2001). However, the uncertainty must take into account when trying to transform the elastic properties into reservoir properties. Precise and accurate relationship should be established between elastic and reservoir properties to overcome the uncertainty.

The study area (Sawan gas field) is a part of middle Indus basin and is located on the south-eastern side of regional Jacobabad and Khairpur Highs (Fig. 1). This area comprises mostly structural-cum-stratigraphic traps which were developed during the inversion of JacobabadKhair highs (Ahmad et al., 2004; Berger et al., 2009). This inversion has changed the structural framework of the area due to which conventional structural interpretation provides no leads (Ahmad and Chaudhry, 2002). However, the logging and drilling results confirm that the sands of early Cretaceous age of Lower Goru formation are proven reservoir rocks in the middle and lower Indus basin (Ahmad et al., 2004). Ibrahim (2007) and Afzal et al. (2009) studied the area based on amplitude anomalies however, their studies cover the eastern side of the study area whereas a significant potential is untapped towards

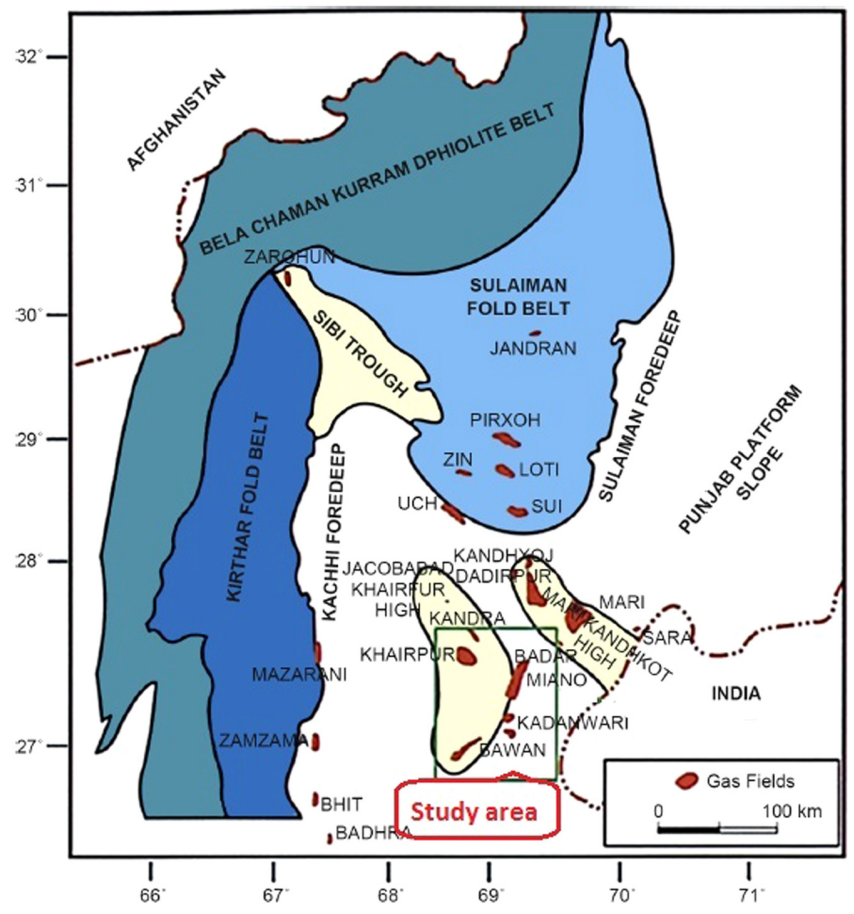

Figure 1. Regional tectonic map showing the location of Sawan Gas Field (Krois et al., 1998).

the western side of the area (Munir et al., 2011; Azeem et al., 2015). Thus, available data sets have been integrated through constrained sparse spike inversion in order to accurately demarcate the sweetness zones in the $\mathrm{B}$ and $\mathrm{C}$ sands of this area.

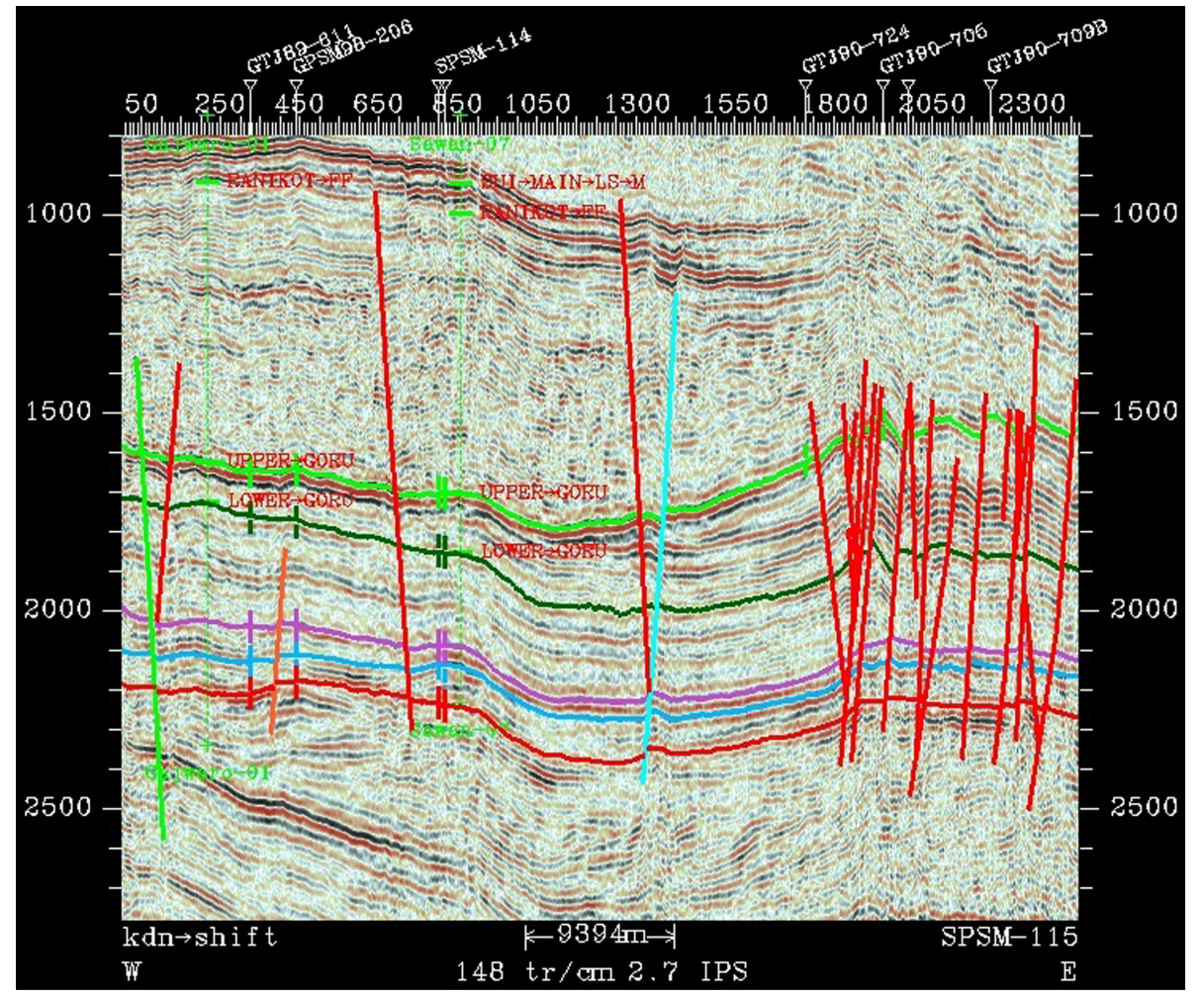

Figure 2. Interpretation of dip oriented seismic line (SPSM 96-115) which shows the extent and orientation of faults and horizons.

\section{Geology of the Area}

\section{Tectonic}

The study area is bounded by Indian shield, Kirther ranges, Suleiman fold and thrust belt and Jacobabad-Khairpur Highs in the East, West, Northwest and South sides respectively (Fig. 1). Structural configuration of this area is the direct result of three post-rifting tectonic events: late Cretaceous uplifting and erosion, basement rooted NNW-SSE oriented wrench faults and late Tertiary to recent uplifting of Jacobabad and Khairpur Highs (Ahmad et al., 2004). The first event occurred near the $\mathrm{K}-\mathrm{T}$ boundary due to the uplifting of Late Cretaceous which was evidenced by the thinning of Ranikot clasts towards the paleohigh and thickening out of these clasts away from it. The termination of majority of basement rooted wrench faults against this unconformity can be identified on the seismic data (Fig. 2) (Ahmad and Chaudhry, 2002).

The second structural event represents the wrench faulting which caused due to the collision 
between Indian and Eurasian plates and the anti-clockwise rotation of Indian plate (Zaigham and Mallick, 2000; Ahmed et al., 2004). The effect of these faults is stronger towards the east of the study area (Fig. 2). These basement rooted NNW-SSE oriented wrench faults cuts the whole Cretaceous section. The character of these faults changes from a single fault at the top of Chilton limestone to multi en-echelon faults near the Upper Goru formation and terminates against the Tertiary unconformity. The throw of these faults is minor and forms a flower-type structure (Fig. 2). A NNW-SSE oriented fault (named as Sawan fault) passing near the left side of Sawan-01 well divides the study area into east and west reservoir compartments (Fig. 3).

The last structural event is the Late Tertiary to recent uplifting of Jacobabad/Khairpur High. The uplifting of these Highs positioned the Lower Goru reservoir quality sand of proximal depositional system into structurally deep areas whereas, non-reservoir quality distal parts are positioned updip to form the traps (Berger et al., 2009). The development of structural and stratigraphic traps along the paleohigh, secondary hydrocarbon migration and reservoir charge took place in this phase (Ahmad et al., 2004).

\section{Reservoir Geology}

Sedimentary rocks of Cretaceous age are widely exposed in different parts of Pakistan. Lithologically these rocks can be characterized into limestone, sandstone and shale. Drilling and logging results show

that complete petroleum system was deposited during Cretaceous period. In the Middle and Lower Indus basin, Sembar and Lower Goru formations are the proven primary source and reservoir rocks respectively (Zaigham and Mallick, 2000). The Sembar Formation of early Cretaceous age was deposited in marine environments. It is mainly composed of thick black shale with subordinate amounts of siltstone, nodular argillaceous limestone and thin beds of sandstone. These sandstones probably derived from Indian Shield, as the eastern part of the basin includes more sand while western part contains more silt and shale (Kadri, 1995). Sembar Formation contains type III kerogen organic matter due to which it is considered as favorable for gas production (Wandrey et al., 2004).

The Sembar formation is overlain by the Lower Goru Formation which acts as a reservoir rock in the Middle and Lower Indus Basin. The upper part of this formation is mainly composed of transgressive shale, siltstone and thin layers of shaly sand. The lower part contains reservoir quality sandstones with thin layers of shale and limestone (Kadri, 1995). These reservoir quality sandstones have been further divided into A, B, C and D sand intervals (Fig. 4). Petrographic analysis depicts that $\mathrm{A}$ and $\mathrm{B}$ sands interval contain quartz arenite, whereas $\mathrm{C}$ interval contains sublithic to lithic arenite (McPhee and Enzendorfer, 2004; Berger et al., 2009). Core sedimentology and seismic stratigraphy studies shows that $\mathrm{C}$ sands can be characterized as lowstand shelf-edge delta system (Ahmed et al., 2004; Afzal et al., 2009; Munir et al., 2011). The Lower Goru is overlain by thick transgressive shale of Upper Goru formation which acts as regional seal.

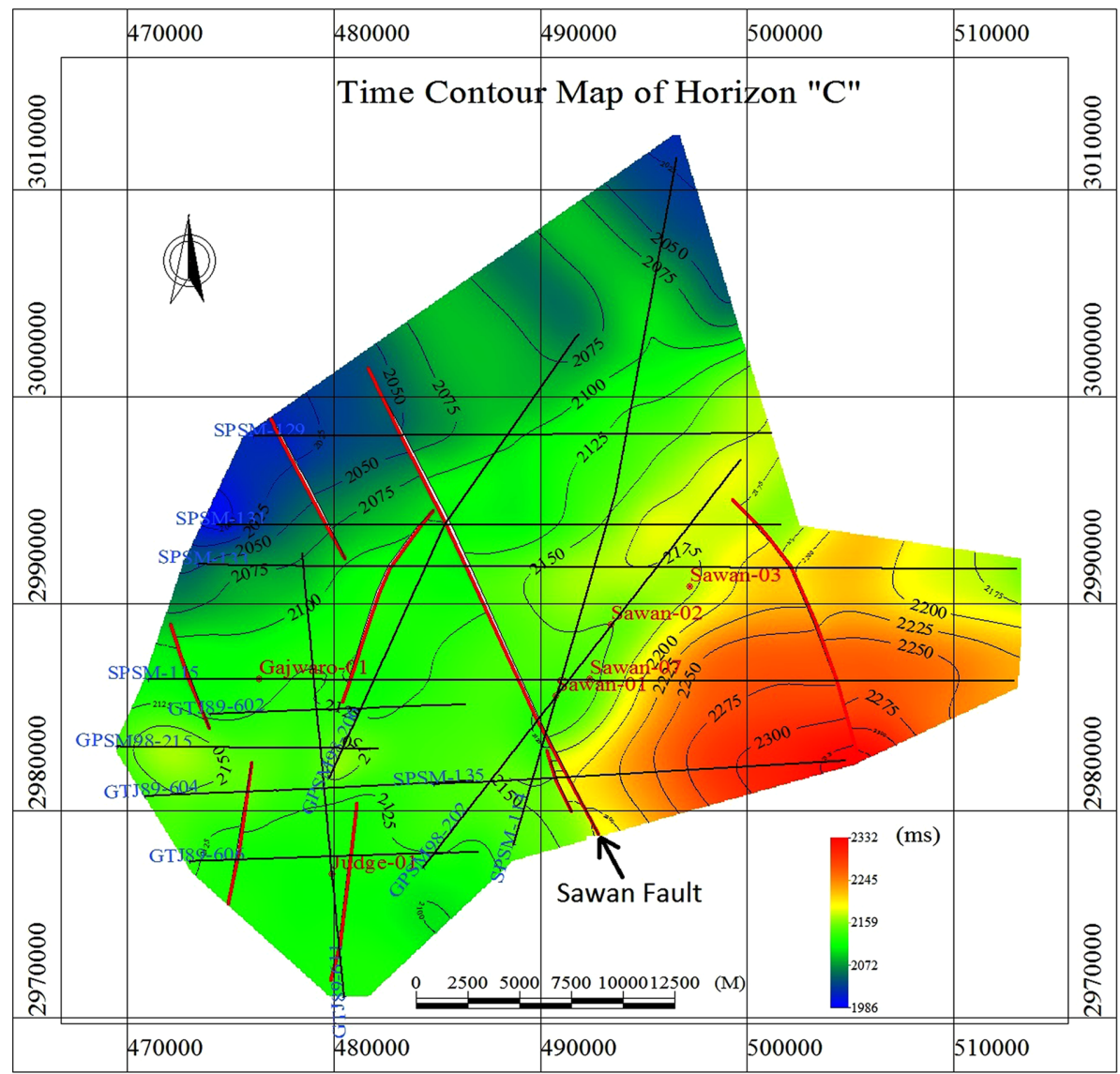

Figure 3. Time contour map of " $C$ " sand, presenting the structural configuration of the study area. The fault which divides the study area into east and west compartments is named as Sawan fault.

\section{Data Set and Methodology}

Constrained sparse spike inversion (CSSI) was performed to integrate the seismic and well $\log$ data sets in order to delineate the sweetness zones. The data sets include thirteen 2D poststack seismic lines and six wells. The orientation of 2D seismic lines and position of wells are shown in Figure 3. The available wells include complete suits of wireline well logs such as GR, DT, SP NPHI, LLD, LLS and RHOB etc. This work has been completed in following steps.

- In the first step, petrophysical and conventional seismic data interpretation was carried out.

- In the second step well logs, petrophysical parameters, seismic data and seismic horizons were integrated through constrained sparse spike inversion (CSSI) in order to find the accurate and precise reservoir model. For this purpose, seismic to well tie for each well was performed and a best suitable wavelet has been extracted. Extracted wavelet, well logs, seismic data and seismic horizons were used to develop the low frequency earth model. Since CSSI provide band limited results so, low frequency 


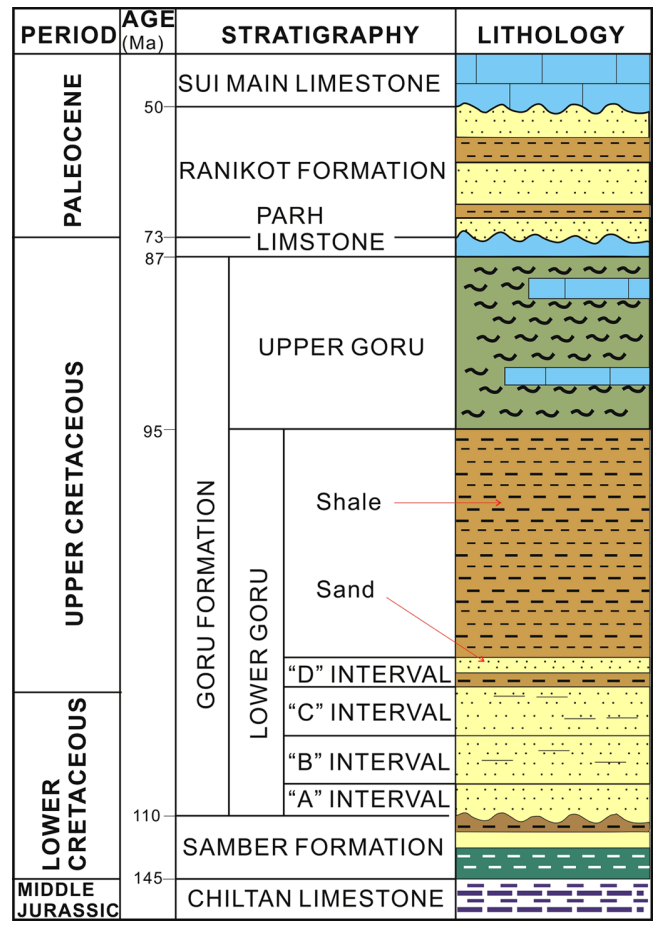

Figure 4. Stratigraphic column representing the shale and sand intervals (A, B, C and D sand intervals) of Lower Goru Formation modified after Krois et al. (1998). earth model was merged with band limited inverted impedance model to improve the resolution. Different quality control tests were applied to check the validity of inversion results.

- In the third step, impedance maps for the "B" and "C" sands (horizons) were developed and distribution of reservoir quality sands in these sand intervals were analyzed in the whole study area.

- Finally, a relationship between impedance and porosity values was developed and then it was used to convert the impedance model into porosity. The validity of porosity results were checked with the help of core data and blind well test.

\section{Results and Discussions}

\section{Petrophysical Analysis}

Wireline logs such as gamma ray (GR), spontaneous potential (SP), caliper (Cali), density (RHOB), Neutron porosity (NPHI), sonic (DT), shallow and deep resistivity logs (LLS and LLD) were displayed in different tracks as shown in Figure 5. On the basis of these logs, Azeem et al. (2017) carried out a comprehensive study in order to identify the payable reservoir zones. Their analysis (Fig. 5) clearly indicate that the upper portion of the composite logs show high values of volume of shale $\left(V_{s h}\right)$, water saturation $\left(S_{w}\right)$, low value of effective porosity (PHIE) and false crossover between density and neutron porosity logs

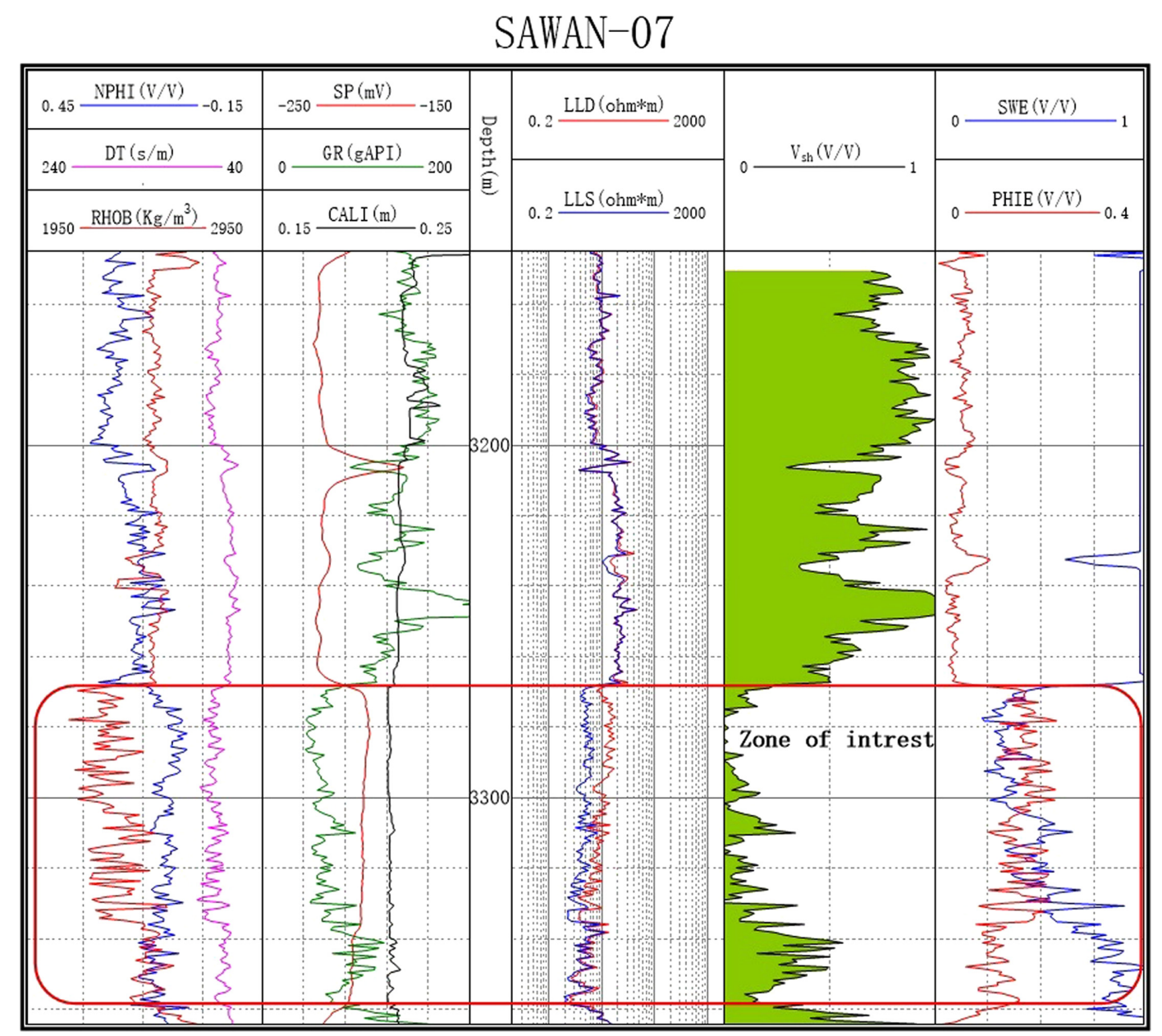

Figure 5. Identification of reservoir zone based on composite logs and peterophysical analysis (Azeem et al., 2017). 


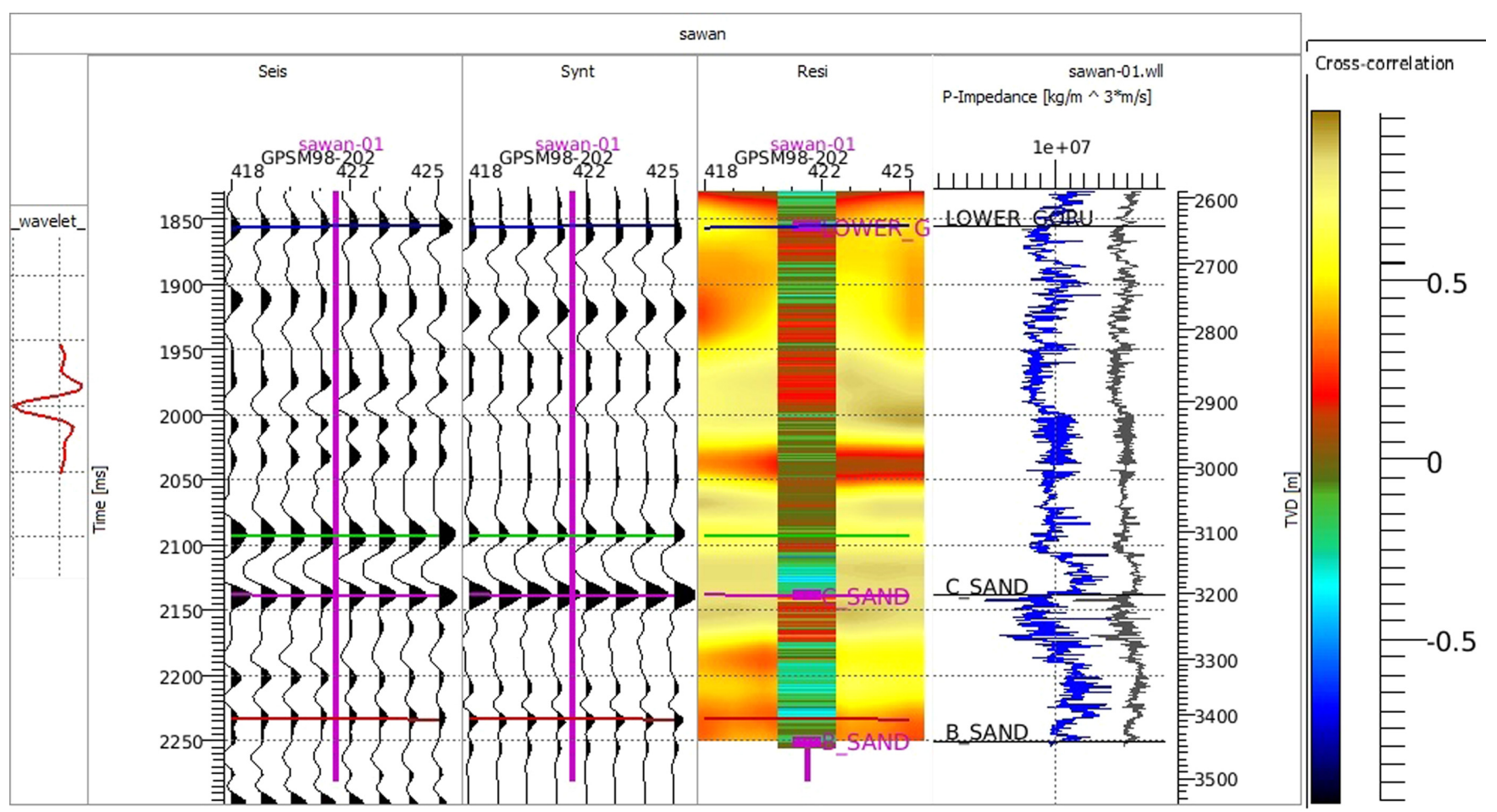

Figure 6. Seismic to well tie, yellow color indicates highest value of cross correlation while blue color indicates to low correlation between seismic and synthetic traces.

which depicts that the upper portion of the Lower Goru formation is composed of non-reservoir quality thick shale. However, petrophysical results show that few thin beds of tight shaly sand also present in this upper part. Whereas, in the lower portion, the decrease in volume of shale and water saturation values and increase in effective porosity values confirm that this porous sand (reservoir quality sand) zone is favorable for hydrocarbons accumulation. The large crossover between density (RHOB) and neutron porosity (NPHI) logs shows the presence of gas in this reservoir zone. In this well the top level of $\mathrm{C}$ sand was observed at the depth of $3268 \mathrm{~m}$ and $\log$ data analysis shows that this point is the start of payable reservoir zone which goes further deeper up to B sand in the study area.

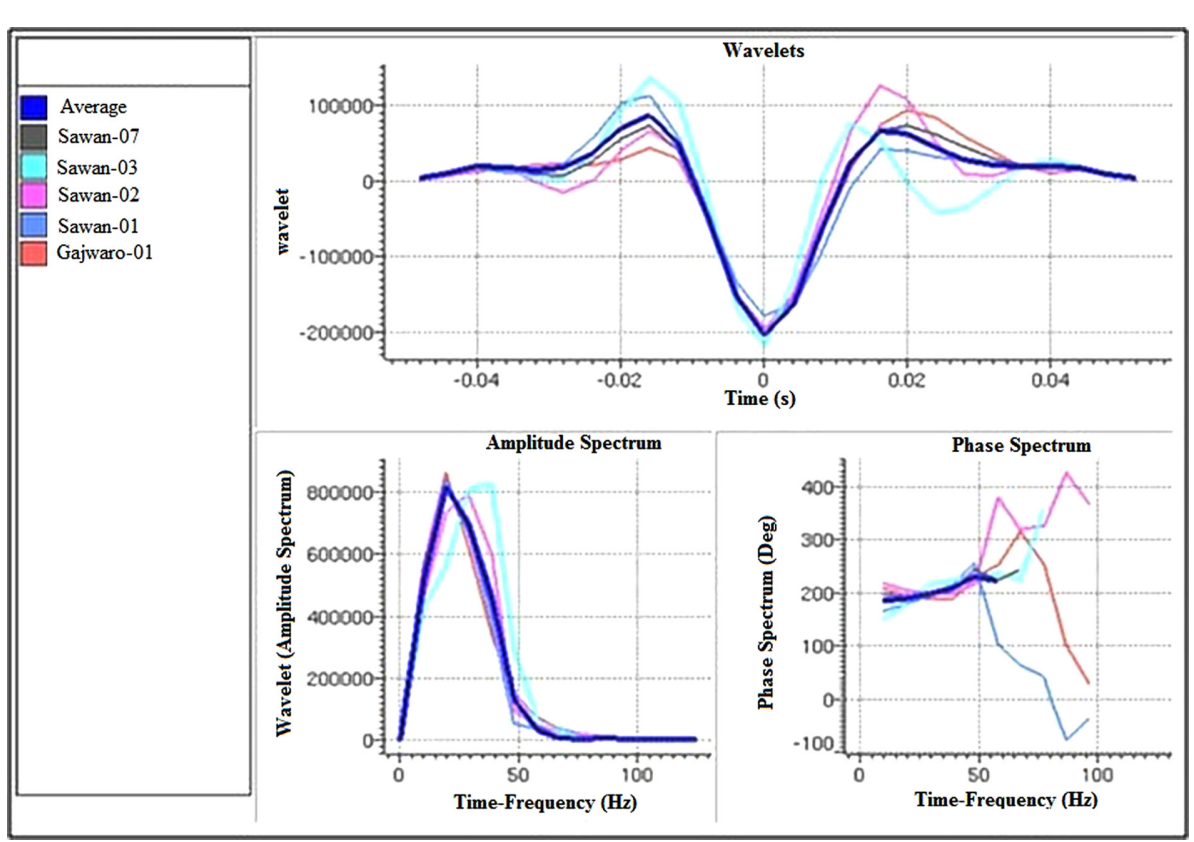

Figure 7. Extracted seismic wavelet, amplitude spectrums and phase spectrums of all wells. Blue line represents to average value.

\section{Seismic Inversion}

\section{Seismic to well tie and wavelet estimation}

Seismic to well tie is a process of finding the relationship between time and depth domains. It means to correlate the geological features with the corresponding seismic reflections. More importantly it plays an important role to estimate the seismic wavelet which is the fundamental part of seismic inversion (Allouche et al., 2009). All the available wells in the target area were calibrated with the specific $2 \mathrm{D}$ seismic lines which pass through the corresponding wells location. For this purpose sonic and density logs were used to get the acoustic impedance and reflectivity logs then a Ricker wavelet having $30 \mathrm{~Hz}$ dominant frequency and 180 degree phase was convolved with the reflectivity logs to obtain the synthetic seismograms. Obtained synthetic traces were compared with the corresponding seismic traces to establish 


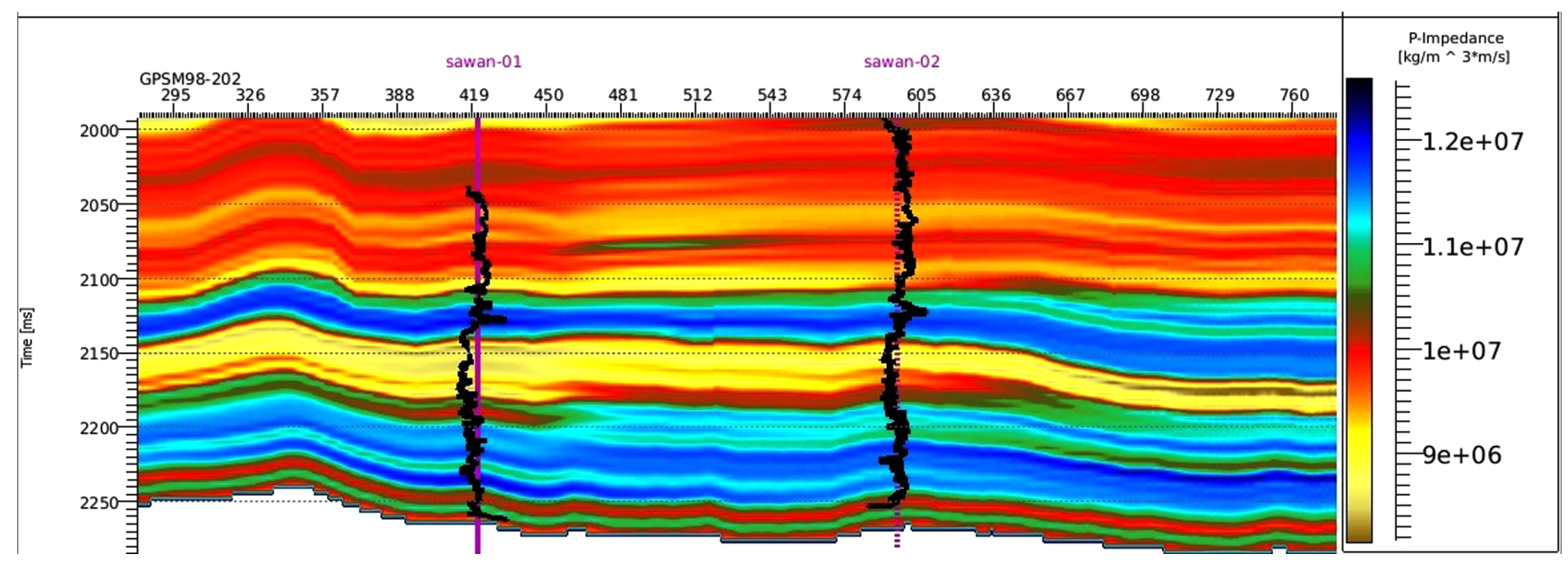

Figure 8. Earth model presenting the lateral as well as vertical variations in impedance and their matching with gamma ray log.

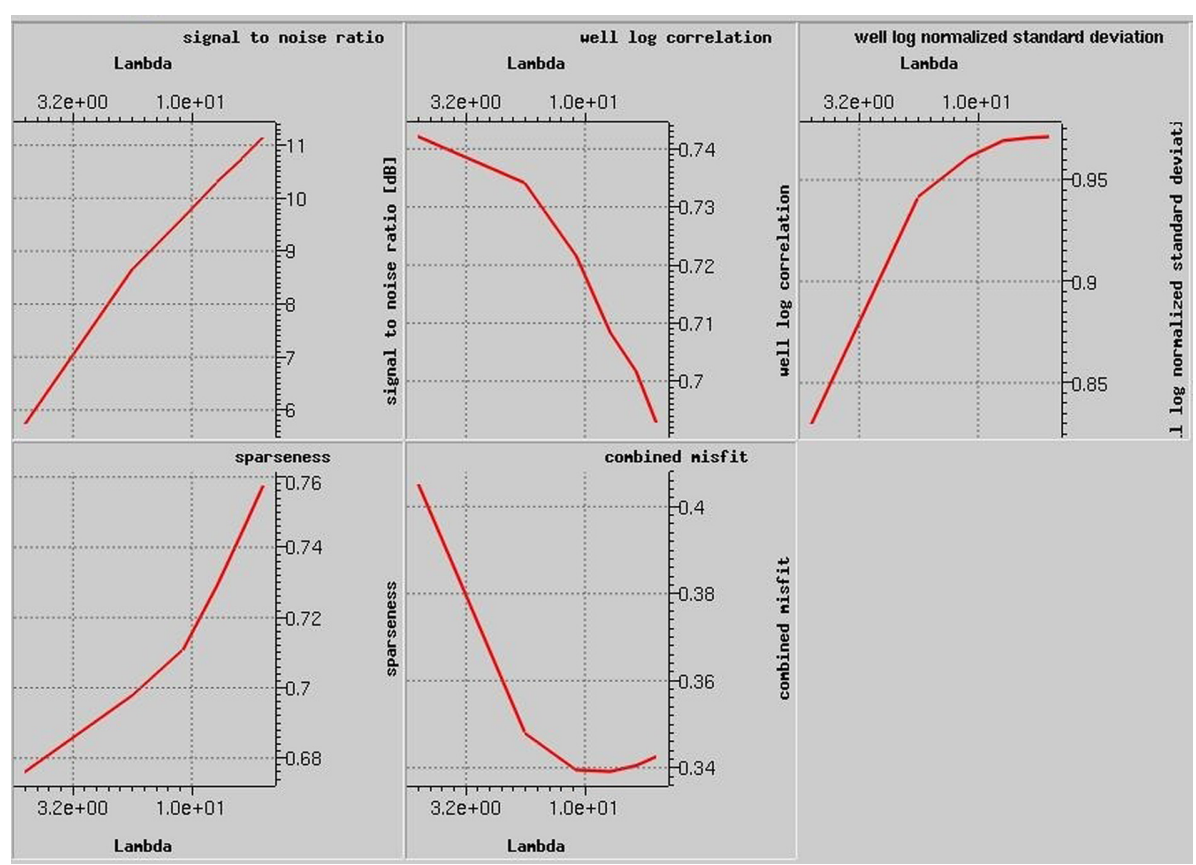

Figure 9. Lambda test to check the influence of lambda value on different seismic inversion parameters.

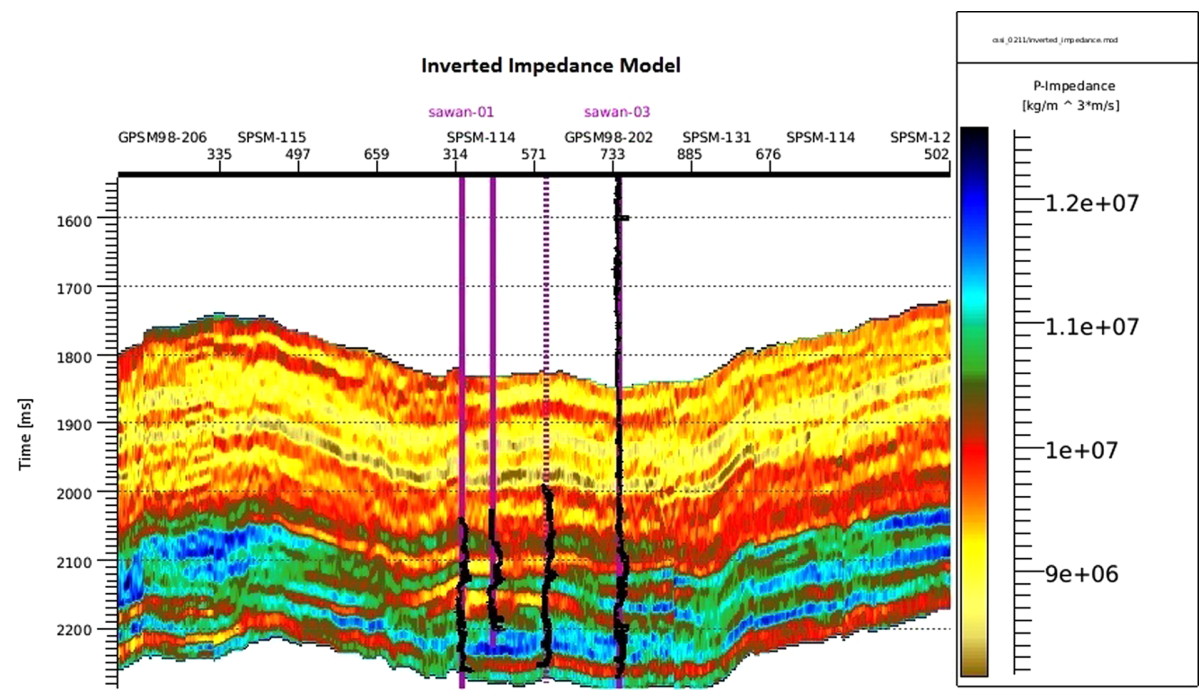

Figure 10. Inverted impedance model based on constrained sparse spike inversion. the link between seismic and well log data. To improve the quality of seismic to well tie necessary stretch, squeeze and vertical time shifts were applied on the corresponding synthetics. These shifts were applied again and again until a good tie was obtained (Fig. 6). During the stretching and squeezing process, an extra care was made as suggested by Nikee et al. (2000) that the obtained time depth relationship must show consistency with the local area results and the change in average velocity due to the stretching of well logs must follow the local geological features. Similar procedure was repeated for each available well.

After performing seismic to well tie, seismic data, acoustic impedance logs and specific time gate (time gate covers the thickness of Lower Goru formation) were used to estimate the wavelet, phase and amplitude spectra. The estimated wavelet from each well was combined to obtain the average wavelet. Figure 7 shows the wavelet shape, amplitude and phase spectrums of the extracted wavelet. The obtained wavelet clearly shows $180^{\circ}$ phase and very smooth response spectra. High correlation value $(>0.76)$ confirms the good matching of seismic and synthetic traces. The good matching of Lower Goru, B, C and D sands tops with the corresponding seismic reflectors (Fig. 6) and the accurate estimation of wavelet (Fig. 7) confirms the reliability and accuracy of this work which will lead to accurately interpret the lithology, sweetness zones and subtle stratigraphic traps (Ziolkowski et al., 1998).

\section{Earth model/low frequency model}

The presence of low frequency noises in the seismic data contaminates the low frequency 
information as a result recorded seismic data misses low frequency information. To recover the low frequency information, well log, seismic wavelet, seismic data and seismic horizons were merged through Ferguson and Margrave (1996) algorithm. This algorithm is based on iterative forward modeling approach (Veeken and Silva, 2004). It computes the low frequency information by integrating the detailed well $\log$ information and band limited seismic data. However, the accuracy of these recovered information depend upon the accurate estimation of seismic wavelet and proper adjustment of weighting parameters.

In the first step, framework is developed to describe the order of horizons and orientation of faults. Then the fine detailed well log information was interpolated between the wells and along the horizons by using triangulation interpolation technique. The obtained model clearly shows the vertical as well as lateral variations within the whole Lower Goru formation (Fig. 8). It is based on P-impedance log information. Vertical variations in impedance are related to change in lithology whereas lateral variations show the extent of different facies.

\section{Constrained sparse spike inversion}

Constrained sparse spike inversion (CSSI) was performed to obtain

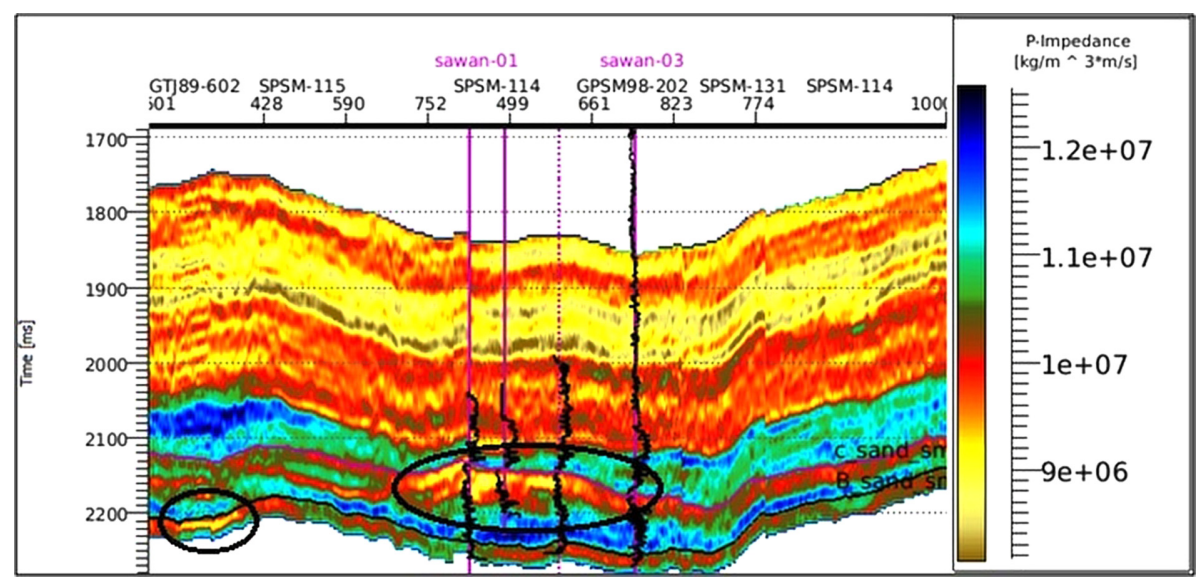

Figure 11. Acoustic impedance model after merging low frequency information. Black circles indicate low impedance sweetness zones. the band limited inverted acoustic impedance model. CSSI considers each trace of seismic data as a set of reflection coefficient which need to be convolved with estimated wavelet. More importantly CSSI uses a set of inversion constrains based on available information which reduces the non-uniqueness and produces an accurate and simplest impedance model (Wang and Guo, 2008). CSSI inversion was completed in following steps; 1) estimation of reflection coefficient series at each trace, 2) convolution of estimated reflection coefficients series with estimated seismic wavelet, 3) proper adjustment of CSSI controlling parameters and 4) estimation of acoustic impedance.

CSSI is based on minimize objective function which can be expressed as follow

$$
F=L_{p}(r)+\lambda L_{q}(s-d)+\alpha^{-1} L_{1}\left(\Delta z_{\text {trend }}\right)
$$

where $F$ represents to minimize objective function, $r$ reflection coefficients, $s$ synthetic data, $d$ seismic data, $\lambda$ data mismatch weighting factor, $\alpha^{-1}$ uncertainty related to soft trend constraint, $\Delta z_{\text {trend }}$ trend mismatch whereas, $L_{p}, L_{q}$ and $L_{1}$ represent to norms of reflectivity misfit, seismic data misfit and trend mismatch respectively.

The synthetic data can be obtained by convolving estimated seismic wavelet with the reflection coefficient series as expressed

$$
s=w^{*} r
$$

$W$ and $r$ represent to estimated seismic wavelet and reflection coefficient respectively. The series of reflection coefficient can be obtained by using following equation

$$
r_{i}=\frac{z_{i+1}-z_{i}}{z_{i+1}+z_{i}} .
$$

In the above equation $Z$ represents to acoustic impedance and the subscript "l" represent to reflection coefficient sample index.

The spikiness was controlled by adjusting the values of Lambda $(\lambda)$ factor. The accurate estimation of lambda value gives the balance

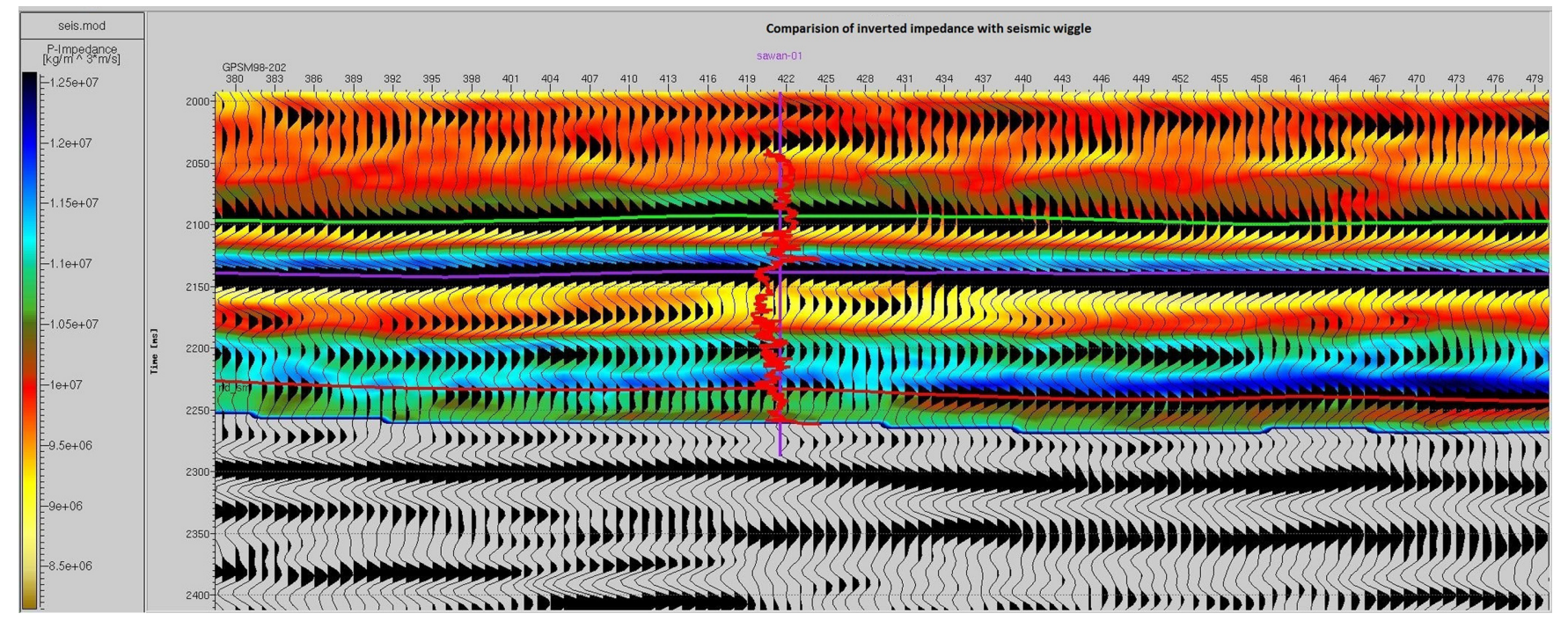

Figure 12. Overly of seismic section (wiggle) and inverted acoustic impedance (Line SPSM 96-202) along with gamma ray log. 
between inverted impedance trace and seismic data set. During the selection of lambda value it has been observed that low value of lambda does not explain the data satisfactorily whereas, high value of lambda contains all information including the noise. So in both cases generated acoustic impedance model does not provide the best geological information (Latimer et al., 2000). Therefore, a number of tests have been performed to choose the suitable value of $\lambda$, finally best suitable value (9.35) was selected and inversion was run by misfit and convergence of lines in Figure 9 confirm the better selection of $\lambda$ value.

After adjusting all these parameters, constrained sparse spike inversion was performed and the inverted band limited acoustic impedance results were obtained (Fig. 10). The gap of low frequency information was filled by merging the low frequency model with CSSI acoustic impedance model. The final model shows an improvement in resolution and more clearly shows variation in acoustic impedance which clearly depicts the lateral extent and thickness of different facies within the whole study area (Fig. 11).

The reliability of inverted acoustic impedance was tested by performing the following two tests. In the first step, inverted acoustic impedance was overlaid by seismic data (Fig. 12). This overly clearly show that both the inverted acoustic impedance and seismic data have similar resolution which depicts that inverted acoustic impedance model is suitable for seismic reservoir characterization. In the second using this value. The high value of signal to noise ratio, low seismic

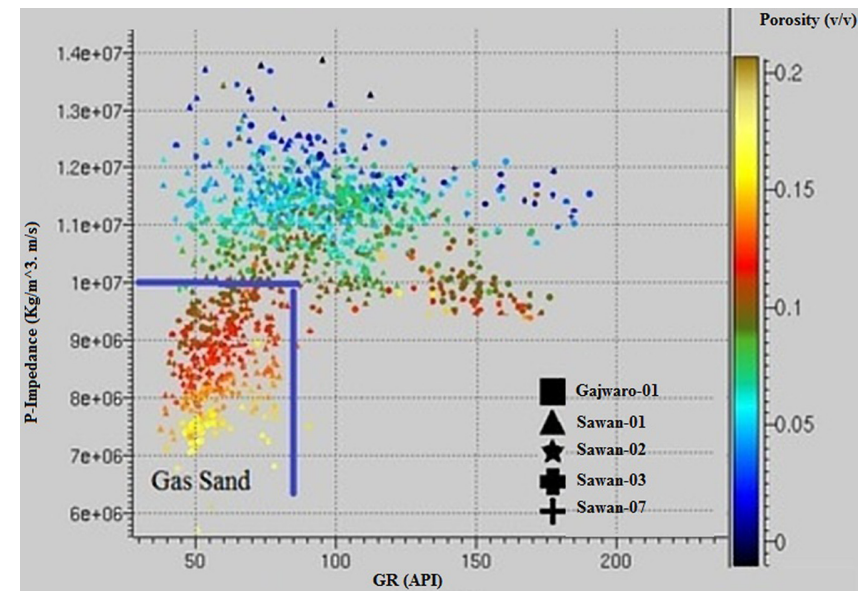

Figure 13. Cross plot between acoustic impedance, gamma ray and porosity logs indicating the cutoff values of gas sand.

step, gamma ray log curves from each well was deployed on the inversion results to validate the reliability of the inversion results as shown in Figures 11 and 12. Gamma ray logs show reasonable matching with inverted acoustic impedance, low gamma ray values (reservoir sand) match with the low impedance (sweet spot) which confirms the credibility of this work. Furthermore, in this area, the low acoustic impedance is coincident with the topset parts of the progradational seismic reflection geometries which are indicative of good quality reservoirs (Ibrahim 2007).

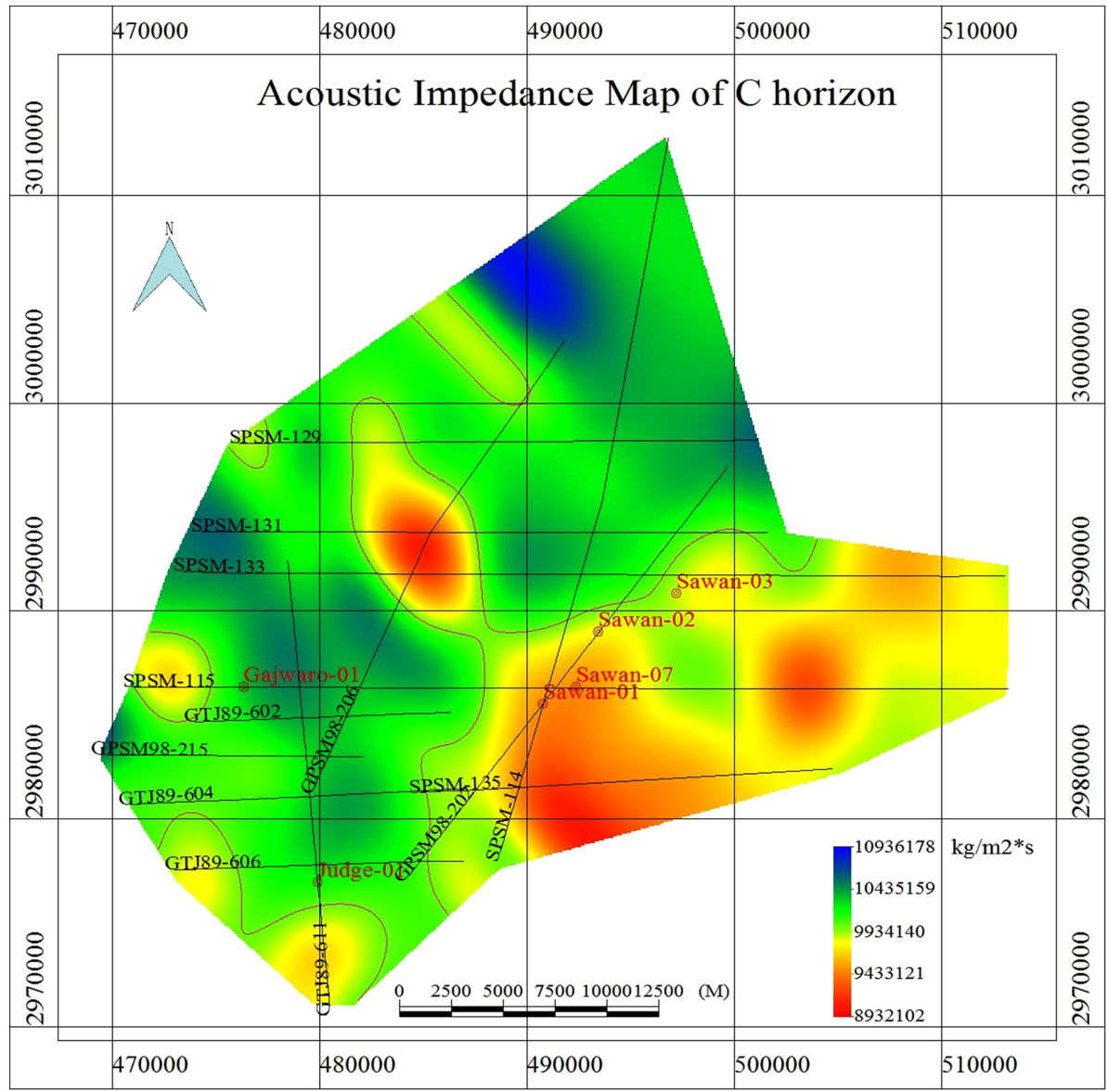

\section{Seismic Reservoir Characterization/ Sweetness Analysis}

Acoustic impedance (product of density and velocity) is a layer property and is closely linked with reservoir properties such as porosity, water saturation, lithology and stratigraphy. Therefore, inverted results were utilized to characterize the Lower Goru " $\mathrm{B}$ " and "C" sands intervals of the study area. In Figure 11 the upper part of this reservoir interval has low acoustic impedance and high gamma ray value which means that upper layer of Lower Goru Formation is composed of shale and this thick layer of shale acts as seal in this area. Below this thick shale, a layer having high impedance and very high gamma ray value was identified. Log analysis shows that this layer may contain heavy minerals. However, in the lower portion some low impedance sweetness zones were identified both in the " $\mathrm{B}$ " and " $\mathrm{C}$ " sands. In " $\mathrm{C}$ " sand this low impedance zone is bounded between two high impedance layers having low gamma ray values as marked by black circle. This low impedance, high quality sand zone acts as gas reservoir in this area, as the producing wells encounter this zone. The thick- 


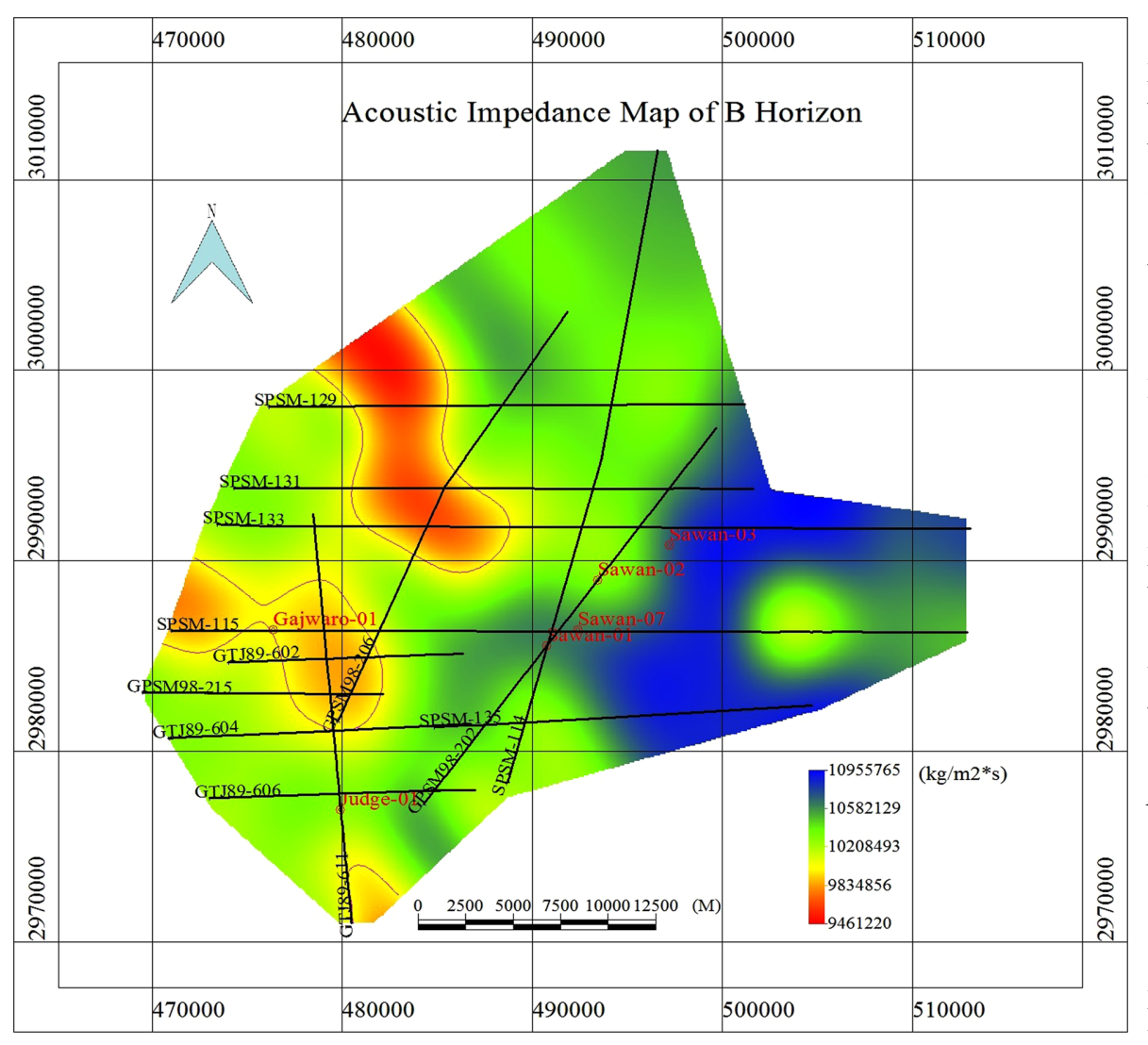

Figure 15. Acoustic impedance map of $B$ horizon (B sand). Zones marked with pink line indicate to low impedance $\left(1.02 \times 10^{7} \mathrm{~kg} / \mathrm{m}^{2} \cdot \mathrm{s}\right)$ sweet zones.

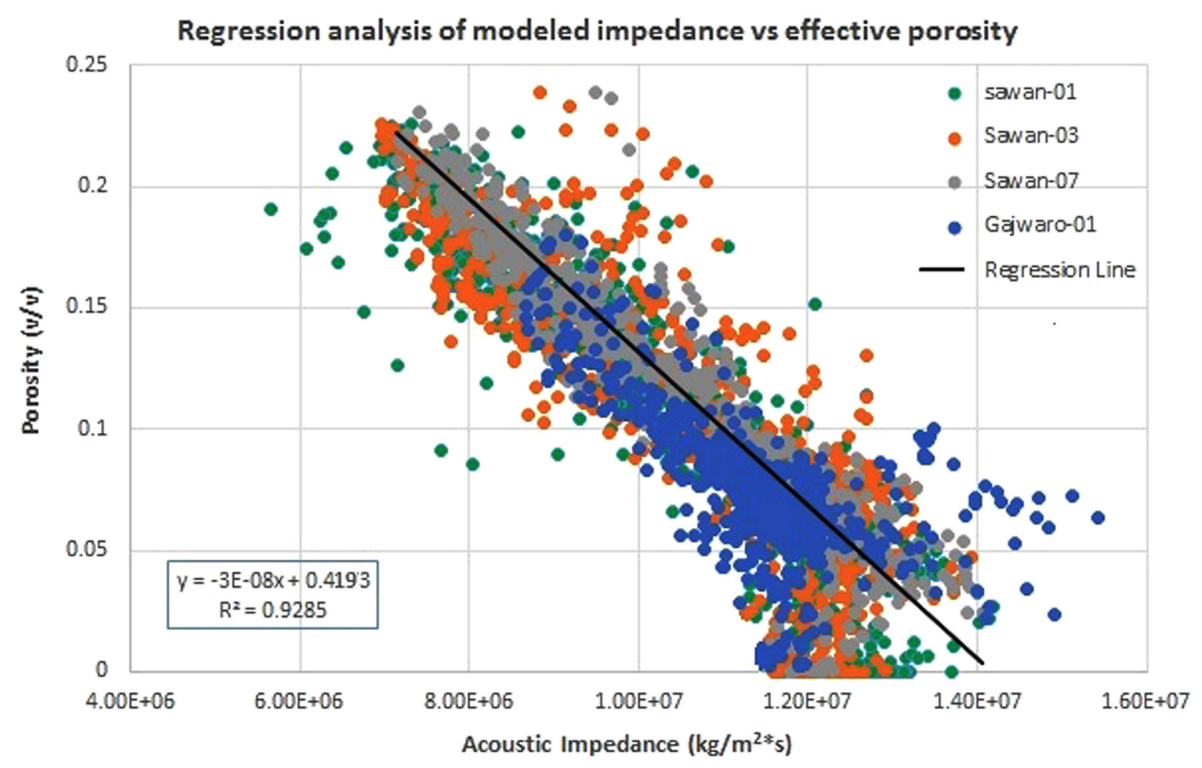

Figure 16. Regression analysis of impedance and porosity logs using Sawan-01, 03, 07 and Gajwaro-1 wells.

ness of this high quality reservoir sand decreases both towards the east and west directions. Another low impedance sand zone located in the "B" sand can be seen in the lower left side of the inverted acoustic impedance model (Fig. 11) marked by black circle. It seems to have similar quality of sand as the $\mathrm{C}$ sand producing zone. However, the vertical thickness and lateral extent of this low impedance zone is lesser than the "C" sand reservoir zone. Petrophysical and elastic parameters have been used to define the cutoff values of different parameters. A cross plot based on porosity, impedance and gamma ray logs was developed as shown in Figure 13. The variation in colors represent to variation in porosity values.

In Figure 13 a cluster of gas filled sand having low acoustic impedance, gamma ray and high effective porosity values is located in the lower left portion of the plot whereas, shale and tight sand sediments are located in the upper portion of the cross plot. From this cross plot it is clear that gas bearing sand has acoustic impedance and gamma ray values less than $1.02 \times 10^{7} \mathrm{~kg} / \mathrm{m}^{2} \cdot \mathrm{s}$ and 80 API respectively whereas, porosity value is greater than or equal to 0.11 .

\section{Acoustic impedance analysis}

The inverted impedance results were utilized to analyze the distribution of gas bearing sand along the "B" and "C" horizons. For this purpose impedance based maps were prepared which cover the whole study area. Figure 14 shows the variation in acoustic impedance along the "C" horizon in the whole study area. The already defined cutoff value for impedance $\left(\leq 1.02 \times 10^{7} \mathrm{~kg} / \mathrm{m}^{2} \cdot \mathrm{s}\right)$ was used to mark the boundary of sweet spots (gas bearing sand zones) as shown in Figure 14. In "C" sand four sweet spots were identified and marked with pink line. The main sweetness zone is located towards the east of Sawan fault which covers an area of $167 \mathrm{~km}^{2}$ whereas; three subtle traps were identified towards the west of Sawan fault which cover an area of $33 \mathrm{~km}^{2}, 6 \mathrm{~km}^{2}$ and $11 \mathrm{~km}^{2}$ respectively. Figure 14 clearly shows that in " $C$ " sand the major distribution of sweetness is towards the east of Sawan fault. The location of gas producing wells (Sawan01, 02, 03 and 07) within sweetness zone and the location of non-producing wells (Gajwaro01 and Judge-01) outside the sweetness zones (in high acoustic impedance zone) confirms the credibility of this work. Furthermore, variation in acoustic impedance values near the producing wells show the extent of good quality sand. These variations can also be linked with the reservoir thickness.

In "B" sand (Fig. 15) three sweetness zones were identified towards the west of Sawan fault whereas the producing wells (Sawan-01, 02, 03 and 07 wells) and Judge- 01 well (non-producing) are located in the high impedance zone which means " $\mathrm{B}$ " sand is not productive in these areas. However, non-producing Gajwaro-01 well is located at the edge of 


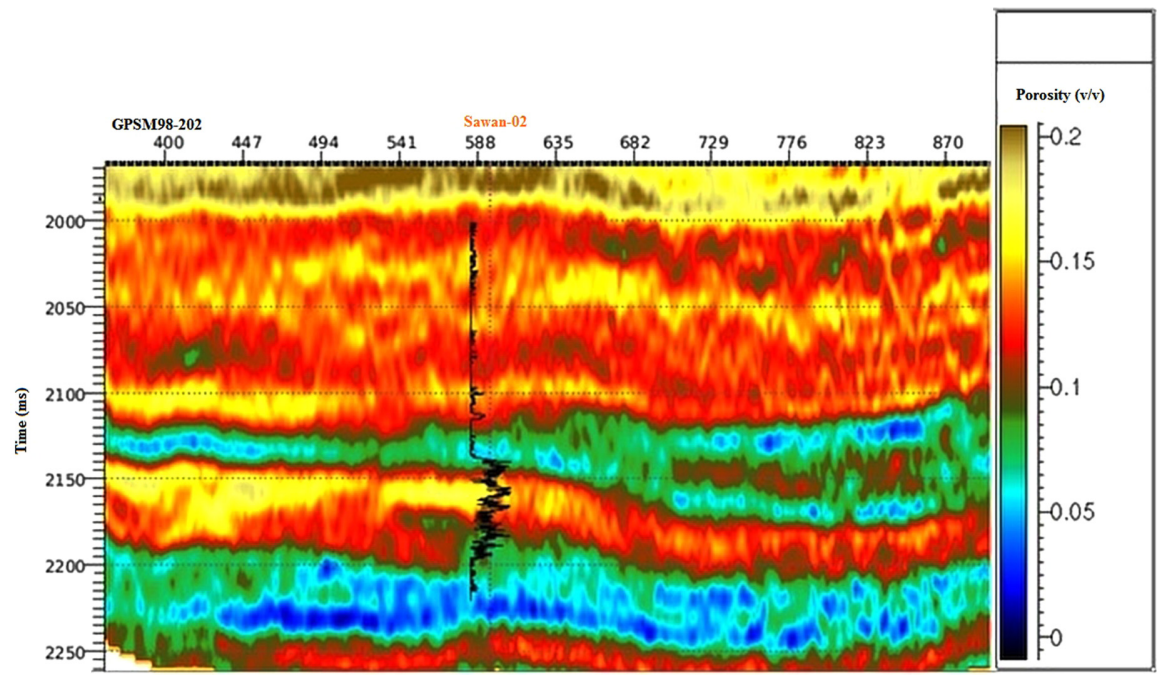

Figure 17. Comparison of estimated porosity with log porosity (porosity log from Sawan-02 well is deployed).

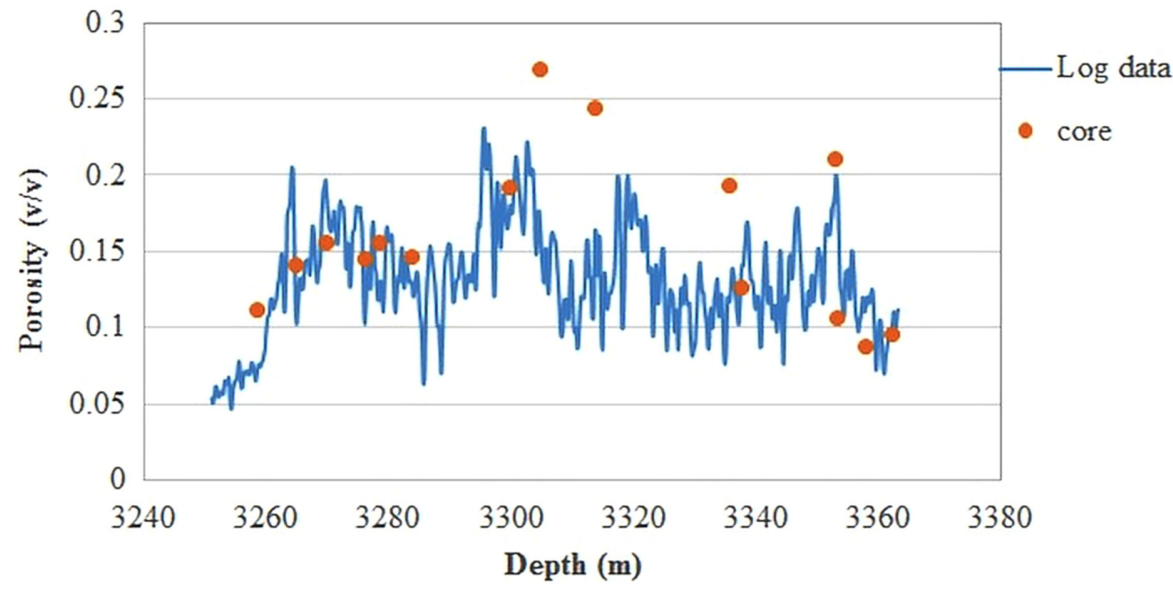

Figure 18. Comparison of core and estimated porosities within the target interval. with porosity (Hampson et al., 2001). Therefore, acoustic impedance and porosity logs from Gajwaro-01, Sawan-01, 03 and 07 wells were cross plotted and regression analysis were performed as shown in Figure 16. Cross plot shows a linear relationship with negative slope and high correlation value (92.85\%) between acoustic impedance and porosity logs. This high correlation value confirms the credibility of the obtained linear relationship.

This obtained equation was utilized to convert the inverted acoustic impedance sections into porosity as shown in Figure 17. During the process of regression analysis the porosity log from Sawan-02 well was not used. The idea was to utilize it as blind well in order to check the validity of the estimated porosity. The porosity $\log$ curve of this blind well (Sawan-02) was then displayed on the seismic section which shows reasonable matching with the inverted porosity section (Fig. 17).

However, the most reliable test is to match the calculated reservoir properties with the core data. For this purpose the pseudo porosity $\log$ at the position of Sawan-02 well was extracted then these extract porosity values were compared with the core porosity data. Core results were obtained from the published study of Berger et al. (2009). In that study, they analyzed fifteen core samples from Sawan-02 well (Table 1); we took advantage of his study and compared obtained porosity results with core data as shown in Figure 18. Comparison depicts that inverted porosity results show very good matching with core data. Out of fifteen core sam- low impedance zone as shown in Figure 15. The studies of Munir et al. (2011) and Azeem et al. (2015) also support our results. This sweetness zone covers an area of $49 \mathrm{~km}^{2}$ and seems to be favorable for gas. Another low impedance zone is located at the intersection of lines SPSM 131, 133 and GPSM-96-206 covering an area of $71 \mathrm{~km}^{2}$. It looks like the mirror image of "C" sand sweetness zone with some lateral extent towards northwest direction. One subtle sweet spot is located at the south of Judge- 01 covering an area of $4 \mathrm{~km}^{2}$. Overall "B" sand exhibits bit higher acoustic impedance values than $\mathrm{C}$ sand.

\section{Porosity analysis}

Acoustic impedance is rock property and has direct relationship ples, twelve samples show good matching with the inverted porosity values. This reasonable matching of core and estimated porosities confirm the reliability of this work.

The inverted porosity values were then used to develop the porosity maps of "B" and "C" sands in order to check the variation in porosity within the whole study area (Figs. 19 and 20). In "C" sand the western part of the study area mostly have low porosity value instead of few subtle zones which show high porosity values whereas, eastern part have good porosity and producing wells are also located in the high porosity zone. Sawan-01 and Sawan-07wells are located in the higher porosity zones whereas; Sawan-02 andSawan-03 wells are located comparatively in moderate porosity zones. However, porosity map of $\mathrm{B}$ sand represent different scenario than $\mathrm{C}$ sand. In B sand western

Table 1. Core porosity values of Sawan-02 well within the reservoir zone

\begin{tabular}{|c|c|c|c|c|c|c|c|c|}
\hline Depth & 3258.6 & 3264.6 & 3269.6 & 3275.9 & 3278.3 & 3283.6 & 3299.5 & 3304.5 \\
\hline Porosity & 0.1123 & 0.1422 & 0.156 & 0.1453 & 0.1557 & 0.1466 & 0.1922 & 0.2694 \\
\hline Depth & 3313.6 & 3335.5 & 3337.7 & 3352.9 & 3353.02 & 3357.9 & 3362.3 & \\
\hline Porosity & 0.2446 & 0.1941 & 0.1271 & 0.2107 & 0.107 & 0.088 & 0.096 & \\
\hline
\end{tabular}




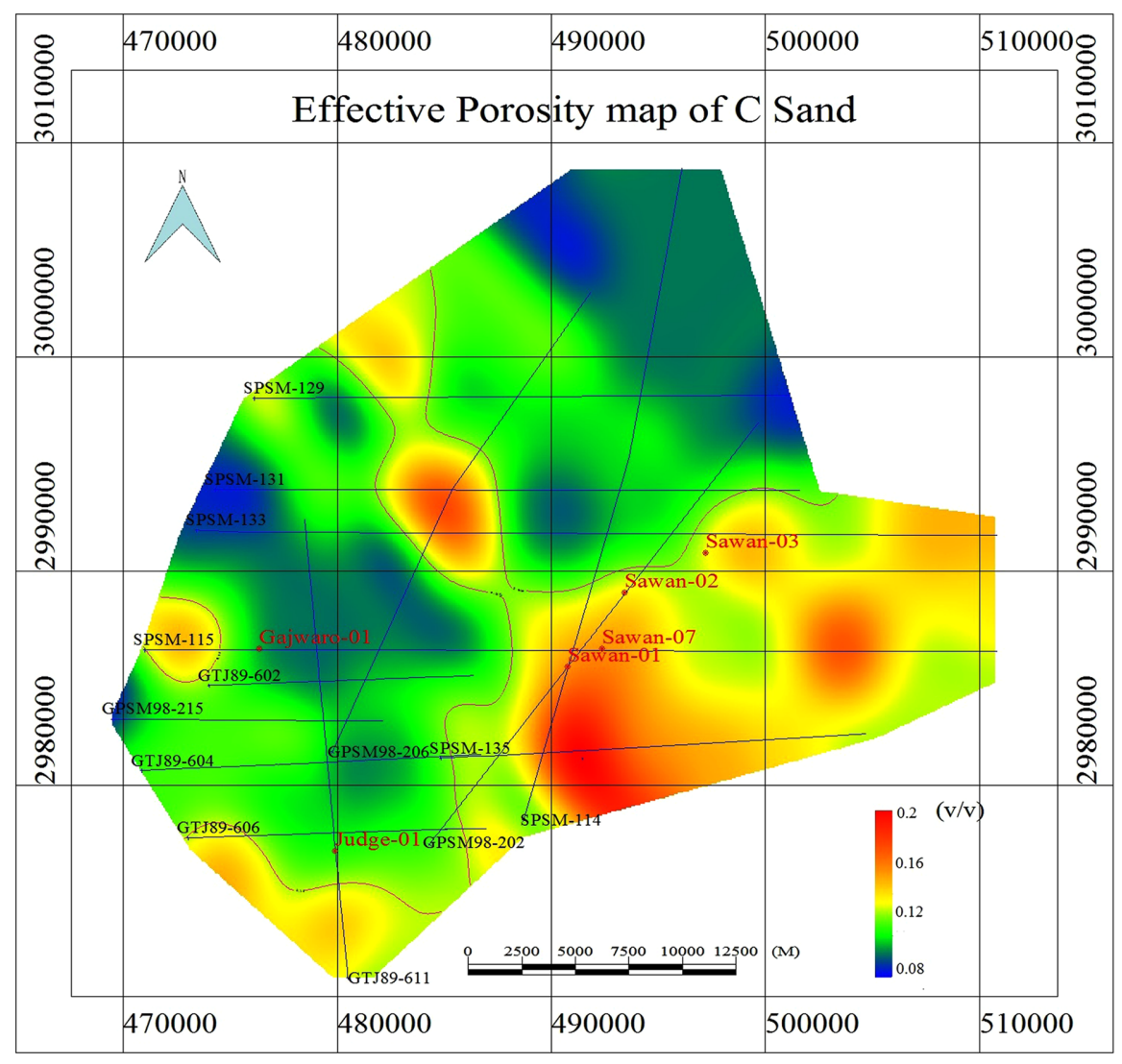

Figure 19. Porosity map of C horizon (C sand), Zones marked with pink line have porosity values $\geq 0.11 \mathrm{~V} / \mathrm{V}$.

\begin{tabular}{|c|c|c|c|c|c|c|}
\hline & 470000 & 480000 & 490000 & 500000 & 510000 & \\
\hline $\begin{array}{l}8 \\
8 \\
\frac{8}{0} \\
\text { m }\end{array}$ & & Effect & rosity N & B Sand & & $\begin{array}{l}8 \\
8 \\
0 \\
0 \\
m\end{array}$ \\
\hline $\begin{array}{l}8 \\
8 \\
8 \\
8 \\
m\end{array}$ & & & & & & $\begin{array}{l}8 \\
8 \\
8 \\
8 \\
\end{array}$ \\
\hline $\begin{array}{l}8 \\
\varnothing \\
\vdots \\
\text { ते } \\
\text { ते }\end{array}$ & & & & & & $\begin{array}{l}8 \\
8 \\
\circ \\
\text { बे }\end{array}$ \\
\hline $\begin{array}{l}8 \\
8 \\
8 \\
8 \\
\text { 1े }\end{array}$ & & & & & & 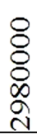 \\
\hline $\begin{array}{l}8 \\
\frac{8}{2} \\
\frac{2}{2} \\
\end{array}$ & & GUS & & 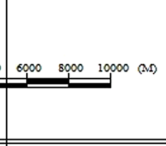 & $\begin{array}{l}0.12 \\
0.08 \\
0.04\end{array}$ & $\begin{array}{l}8 \\
\frac{8}{2} \\
\frac{2}{2}\end{array}$ \\
\hline & 470000 & 480000 & 490000 & 500000 & 510000 & \\
\hline
\end{tabular}

Figure 20. Porosity map of B horizon (B sand), Zones marked with pink line have porosity values $\geq 0.11 \mathrm{~V} / \mathrm{V}$. part of the study includes some high porosity zones whereas, eastern part exhibits low porosity values. Overall porosity and acoustic impedance maps of $\mathrm{B}$ and $\mathrm{C}$ sand show the similar results. So it is obvious from these results that $\mathrm{C}$ sand is more productive towards eastern side of the study area whereas, B sand has some sweet spots towards western part of the study area. However, "B" sand shows bit lower porosity values than " $C$ " sand.

\section{Conclusions}

The distribution of sweetness in the $\mathrm{B}$ and $\mathrm{C}$ sands was analyzed by integrating the seismic and well $\log$ data sets. In $\mathrm{C}$ sand four Sweetness zones were identified, the major sweetness zone having an area of $167 \mathrm{~km}^{2}$ is located towards the east of Sawan fault whereas, three minor sweetness zones are located towards the west of the Sawan fault covering an areas of 33 $\mathrm{km}^{2}, 11 \mathrm{~km}^{2}$ and $6 \mathrm{~km}^{2}$. The location of producing and non-producing wells in the sweetness zones and outside the sweetness zones confirms the credibility of this work. B sand includes three sweetness zones, located towards the west of Sawan fault covering an area of 71, 49 and $4 \mathrm{~km}^{2}$. Relationship between porosity and acoustic impedance was developed with the help of regression analysis which shows a high degree of matching (92.85\%), the high correlation value premise that the obtained linear relationship is feasible to calculate the porosities of "B" and "C" sands. The estimated porosities not only show good agreement with the blind well (Sawan-02) porosities but also show reasonable matching with the core porosities. Overall in "C" sand major distribution of sweetness was observed towards the eastern side of Sawan fault while, in "B" sand sweetness distribution was observed towards the western side of the Sawan fault.

\section{Acknowledgements}

The Directorate General of Petroleum Concession (DGPC) Pakistan is highly acknowledged for providing the data, which has been used to complete this study. The major portion of this work was carried out at Geodetection Lab of China university of Geosciences, Beijing so authors are also thankful to China University of geosciences for providing the lab facilities. We are also thankful to Dr. Mureed 
Hussain, Dr. Liu Xue Qing and Mr. Xie Wei for their valuable suggestions and technical support.

\section{References}

Afzal, J., Kuffner, T., Rahman, A., and Ibrahim, M., 2009, Seismic and well-log based sequence stratigraphy of the early cretaceous, Lower Goru "C" sand of the Sawan gas field, middle indus platform Pakistan. Annual Technical Conference, 2009, Pakistan Association of Petroleum Geoscientists, p. 51.

Ahmad, N., and Chaudhry, S., 2002, Kadanwari gas field, Pakistan: a disappointment turns into an attractive development opportunity. Petroleum Geoscience, v. 8, pp. 307-316.

Ahmad, N., Fink, P., Sturrock, S., Mahmood, T., and Ibrahim, M., 2004, Sequence stratigraphy as predictive tool in Lower Goru Fairway, Lower and Middle Indus Platform, Pakistan. Annual Technical Conference, 2004, Pakistan Association of Petroleum Geoscientists, Abstract No. 90143 , p. 85 .

Ali, A., Alves, T.M., Saad, F.A., Ullah, M., Toqeer, M., and Hussain, M., 2018, Resource potential of gas reservoirs in South Pakistan and adjacent Indian subcontinent revealed by post-stack inversion techniques. Journal of Natural Gas Science and Engineering, v. 49, pp. 41-55.

Allouche, H., Thore, P., and Monnerie, T., 2009, Towards a better seismic to well tie in complex media. SEG Technical Program Expanded Abstract 2009, Society of Exploration Geophysicists, p. 1870. https://doi.org/ 10.1190/1.3255220.

Avseth, P., Mukerji, T., and Mavko, G., 2005, Quantitative Seismic Interpretation - Applying Rock Physics Tools to Reduce Interpretation Risk ( $1^{\text {st }}$ edition). Cambridge University Press, New York, 359 p.

Azeem, T., Yanchun, W., Khalid, P., Xueqing, L., Yuan, F., and Lifang, C., 2015, An application of seismic attributes analysis for mapping of gas bearing sand zones in the sawan gas field, Pakistan. Acta Geodaetica et Geophysica, v. 51, pp.723-744.

Azeem, T., Yanchun, W., Khalid, P., Qing, L.X., Ehsan, M.I., Munawar, M.J., and Wei, X., 2017, An integrated petrophysical and rock physics analysis to improve reservoir characterization of Cretaceous sand intervals in Middle Indus Basin, Pakistan. Journal of Geophysics and Engineering, v. 14, pp. 212-225.

Balch, A.H., 1971, Color sonagrams - a new dimension in seismic data interpretation. Geophysics, v. 36, pp. 1074-1098.

Barclay, F., Bruun, A., Rasmussen, K.B., Alfaro, J.C., Cooke, A., Cooke, D., Salter, D., Godfrey, R., Lowden, D., McHugo, S., and Özdemir, H., 2008, Seismic inversion: reading between the lines. Oilfield Review, v. 20, pp. 42-63.

Berger, A., Gier, S., and Krois, P., 2009, Porosity-preserving chlorite cements in shallow-marine volcaniclastic sandstones: evidence from Cretaceous sandstones of the Sawan gas field, Pakistan. American Association of Petroleum Geologists Bulletin, v. 93, pp. 595-615.

Chi, X., and Han, D., 2009, Lithology and fluid differentiation using rock physics templates. The Leading Edge, v. 28, pp. 60-65

Ferguson, R.J., and Margrave, G.F., 1996, A simple algorithm for bandlimited impedance inversion. CREWES Research Report, v. 8, 10 p.

Filippova, K., Kozhenkov, A., and Alabushin, A., 2011, Seismic inversion techniques: choice and benefits. First Break, v. 29, pp. 103-114.

Grijalba-Cuenca, A., Torres-Verdin, C., and van der Made, P., 2000, Geostatistical inversion of 3D seismic data to extrapolate wireline petrophysical variables laterally away from the well. SPE Annual Technical Conference and Exhibition, 2000, Society of Petroleum Engineers, ID: SPE-63283-MS. https://doi.org/10.2118/63283-MS

Gunning, J., and Glinsky, M.E., 2004, Delivery: an open-source modelbased Bayesian seismic inversion program. Computers \& Geosciences, v. 30, pp. 619-636.

Hampson, D.P., Schuelke, J.S., and Quirein, J.A., 2001, Use of multiattri- bute transforms to predict log properties from seismic data. Geophysics, v. 66, pp. 220-236.

He, F.B., You, J., and Chen, K.Y., 2011, Gas sand distribution prediction by elastic inversion based on rock physics modelling and analysis. Applied Geophysics, v. 8, pp. 197-205.

Huang, H., Zhang, R., Luo, Q., Zhao, D., and Peng, Y., 2009, Subtle trap recognition based on seismic sedimentology - a case study from Shengli Oilfield. Applied Geophysics, v. 6, pp. 175-183.

Ibrahim, M., 2007, Seismic inversion data, a tool for reservoir characterization/modeling, sawan gas field - a case study. Annual Technical Conference 2007, Pakistan Association of Petroleum Geoscientists, Abstract No. 90140 .

Jadoon, S.-U.-R.K., Mehmood, M.F., Shafiq, Z., and Jadoon, I.A.K., 2016, Structural styles and petroleum potential of Miano Block, Central Indus Basin, Pakistan. International Journal of Geosciences, v. 7, pp. 1145-1155.

Kadri, I.B., 1995, Petroleum Geology of Pakistan (1 $1^{\text {st }}$ edition). Pakistan Petroleum Limited, Karachi, 275 p.

Jarvis, K., 2006, Integrating well and seismic data for reservoir characterization: risks and rewards. ASEG Extended Abstracts, 2006, Abstract No. 1, p. 1 .

Khalid, P., Broseta, D., Nichita, D.V., and Blanco, J., 2014, A modified rock physics model for analysis of seismic signatures of low gas-saturated rocks. Arabian Journal of Geosciences, v. 7, pp. 3281-3295. https:// doi.org/10.1007/s12517-013-1024-0

Krois, P., Mahmood, T., and Milan, G 1998, Miano field, Pakistan, A case history of model driven exploration. Proceedings of the Pakistan Petroleum Convention, 1998, PAPG Pakistan Petroleum Convention, Abstract No. 90145 , p. 112

Latimer, R.B., Davidson, R., and Van Riel, P., 2000, An interpreter's guide to understanding and working with seismic-derived acoustic impedance data. The Leading Edge, v. 19, pp. 242-256.

McPhee, C.A., and Enzendorfer, C.K., 2004, Sand management solutions for high-rate gas wells, Sawan field, Pakistan. SPE International Symposium and Exhibition on Formation Damage Control, 2004, Society of Petroleum Engineers, Abstract No. 86535.

Mukerji, T., Jørstad, A., Avseth, P., Mavko, G., and Granli, J.R., 2001, Mapping lithofacies and pore-fluid probabilities in a North Sea reservoir: seismic inversions and statistical rock physics. Geophysics, v. 66, pp. 988-1001.

Munir, K., Iqbal, M.A., Farid, A., and Shabih, S.M., 2011, Mapping the productive sands of Lower Goru Formation by using seismic stratigraphy and rock physical studies in Sawan area, southern Pakistan, a case study. Journal of Petroleum Exploration and Production Technology, v. 1, pp. 33-42.

Nikee, J.Y., Gawthorpe, R.L., and Sharp, I.R., 2000, Sedimentology and sequence stratigraphy of a transfer zone coarse grained delta, Miocene Suez rift Egypt. Sedimentology, v. 47, pp. 1081-1104.

Oldenburg, D.W., Scheuer, T., and Levy, S., 1983, Recovery of the acoustic impedance from reflection seismograms. Geophysics, v. 48, pp. 1318 1337.

Possato, S., Saito, M., Curtis, M.P., and Martinez, R.D., 1983, Interpretation of three-dimensional seismic attributes contributes to stratigraphic analysis of Pampo Oil Field. SEG Technical Program Expanded Abstracts, 1983, Society of Exploration Geophysicists, p. 478.

Sams, M.S., Atkins, D., Said, N., Parwito, E., and Riel, V.P., 1999, Stochastic inversion for high resolution reservoir characterization in the central Sumatra Basin. SPE Asia Pacific Improved Oil Recovery Conference, 1999, Society of Petroleum Engineers. SPE 57620.

Simm, R., and Bacon, M., 2014, Seismic Amplitude: An Interpreter's Handbook ( $1^{\text {st }}$ edition). Cambridge University Press, New York, 271 p.

Varela, O.J., Torres-Verdín, C., and Lake, L.W., 2006, On the value of 3D seismic amplitude data to reduce uncertainty in the forecast of reservoir production. Journal of Petroleum Science and Engineering, v. 50, pp. 269-284.

Veeken, P.C.H., and Da Silva, M., 2004, Seismic inversion methods and some of their constraints. First Break, v. 22, pp. 47-70. 
Wagner, C., Gonzalez, A., Agarwal, V., Koesoemadinata, A., Ng, D., Trares, S., Biles, N., Geco W., and Fisher, K., 2012, Quantitative application of poststack acoustic impedance inversion to subsalt reservoir development. The Leading Edge, v. 31, pp. 528-537.

Wandrey, C.J., Law, B.E., and Shah, H.A., 2004, Sembar Goru/Ghazij composite total petroleum system, Indus and Sulaiman-Kirthar geologic provinces, Pakistan and India. In: Wandrey, C.J. (Ed.), Petroleum Systems and Related Geologic Studies in Region 8, South Asia. U.S Geological Survey Bulletin, 2208-C, 23 p.

Wang, Q.F., and Guo, K., 2008, Constrained sparse spike inversion applied in the reservoir prediction. Well Logging Technology, v. 32, pp. 35-37.

Zaigham, N.A., and Mallick, K.A., 2000, Prospect of hydrocarbon associated with fossil-rift structures of the southern Indus basin, Pakistan. American Association of Petroleum Geologists Bulletin, v. 84, pp. 1833-1848.

Ziolkowski, A., Underhill, J.R., and Johnston, R.G., 1998, Wavelets, well ties, and the search for subtle stratigraphic traps. Geophysics, v. 63, pp. 297-313.

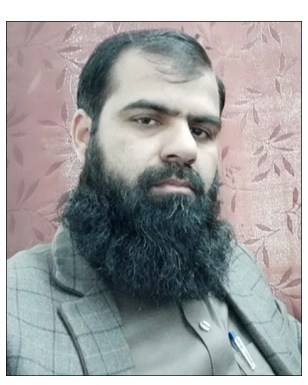

Tahir Azeem is an assistant professor at department of earth sciences, Quaid-i-Azam University Islamabad, Pakistan. He received his Ph.D. degree in geophysics from School of Geophysics and Information Technology, China University of Geosciences, Beijing, China. His research interest includes seismic inversion, rock physics modeling, reservoir characterization and earthquake data analysis.

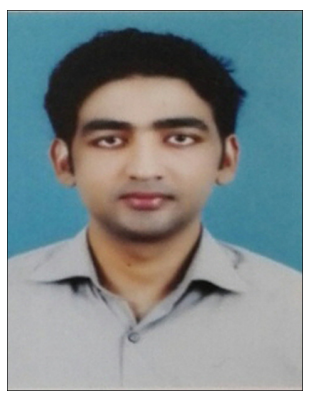

Muhammad Irfan Ehsan is working as Assistant Professor at Institute of Geology University of the Punjab Lahore. He received his Ph.D. Degree in geophysics from School of Geophysics and Information Technology, China University of Geosciences, Beijing, China. 